\title{
The humanitarian common logistic operating picture: a solution to the inter-agency coordination challenge
}

Peter Tatham Professor and Deputy Head of Department, Department of International Business and Asian Studies, Griffith Business School, Australia, Karen Spens Rektor, Hanken School of Economics, Finland, and Gyöngyi Kovács Professor, The Humanitarian Logistics Institute, Hanken School of Economics, Finland

Although significant progress has been made in developing the practice of humanitarian logistics, further improvements in efficiency and effectiveness have the potential to save lives and reduce suffering. This paper explores how the military/emergency services' concept of a common operating picture (COP) can be adapted to the humanitarian logistics context, and analyses a practical and proven approach to addressing the key challenge of inter-agency coordination and decision-making. Successful adaptation could provide the mechanism through which predicted and actual demands, together with the location and status of material in transit, are captured, evaluated, and presented in real time as the basis for enhanced decision-making between actors in the humanitarian supply network. Through the introduction of a humanitarian logistics COP and its linkages to national disaster management systems, local communities and countries affected by disasters and emergencies will be better placed to oversee and manage their response activities.

Keywords: humanitarian common logistic operating picture (H-CLOP), humanitarian logistics, inter-agency coordination

\section{Introduction}

Since the Indian Ocean tsunami on 26 December 2004, there has been growing academic interest in researching the logistic aspects of preparations for, and responses to, disasters and complex emergencies (Kovács and Spens, 2011). This has led to a significant rise in the amount of academic literature, complementing that previously developed by practitioners. A recent review by Leiras et al. (2014), for instance, identified 228 journal articles. Of these, 95 (some 40 per cent) were published after 2008. In addition, an informal bibliography posted on the website of the Humanitarian Logistics and Supply Chain Research Institute at the Hanken School of Economics in Finland now runs to approximately 50 pages. Indeed, the importance 
of the field is underlined by the launch of the Journal of Humanitarian Logistics and Supply Chain Management in 2011.

Within this emerging research field, the definition of humanitarian logistics (HL) that appears most frequently in the literature is that offered by Thomas and Mizushima (2005, p. $60)$ :

The process of planning, implementing and controlling the efficient, cost-effective flow and storage of goods and materials as well as related information, from the point of origin to the point of consumption for the purpose of meeting the end beneficiary’s requirements.

Some might argue that the breadth of such a remit that includes procurement, transport into and within the disaster area, warehousing, and final or 'last-mile' delivery functions is more akin to the concept of supply network (or chain) management, but the HL label has stuck within the practitioner community. HL is, therefore, used in this paper to encompass the management of these functions.

Furthermore, and in line with the above definition, it has been variously estimated that around 60-80 per cent of the income of a humanitarian agency (HA) is spent on logistics (Tatham and Pettit, 2010). It follows that, at least to some extent, HAs are actually managing a logistics operation, albeit one that is challenging and of significant complexity. With this in mind, the observation made more than two decades ago by Christopher (1992) that it is not businesses that compete, but their supply chains, has considerable relevance here. The underpinning principle being that the efficiency and effectiveness of an organisation's logistics networks will impact (positively or negatively) on its success in the market. It is contended that this is equally true of HAs, which are continually searching for ways in which to expend better their limited resources to deliver the services that they are aiming to provide. As will be explained in greater detail later in this paper, one potential way of achieving this is through improvements in inter-agency logistics coordination and associated decision-making. In adopting this approach, one must be mindful of the observation of the current United Nations (UN) Emergency Relief Coordinator, Valerie Amos:

Effective coordination is the hidden force multiplier in emergency response. With coordination, one plus one does not equal three; it equals five or ten. It reduces duplication and competition and allows different agencies and organizations to complement each other and give added value (OCHA, 2014a, p. iii). 
Furthermore, operationalising the challenges faced by the humanitarian logistician is fraught with difficulties. For example, the assessment of demand — who needs what and where? - is, notwithstanding the best efforts of HAs to remain true to the principles of humanity, impartiality, independence, and neutrality (OCHA, 2012a), potentially subject to political influence and the effect of pre-existing power structures.

Importantly, the achievement of successful logistic outcomes involves multiple national and international players, each of which typically utilises their own supply network. Consequently, for instance, the website of the UN Office for the Coordination of Humanitarian Affairs (OCHA) states that more than 900 official HAs are currently (2015) operating in Haiti, while Völz (2005) reported more than 70 coordination meetings per week in Banda Aceh, Indonesia, following the 2004 tsunami. It is accepted that both of these disasters were unusually complex because of their sheer magnitude, yet, at the same time, they underscore the fact that the coordination challenge becomes disproportionately larger when the responders are dealing with such catastrophic events.

Given this plethora of organisations, to which one might add military forces, search and rescue (SAR) teams, and emergency management agencies from both the affected country and from those invited to assist, it is unsurprising that coordination of a disaster/emergency response is seen as one of the most significant challenges facing, in particular, the logistics community (Tatham and Pettit, 2010; Kovács and Spens, 2011). Furthermore, since the focus of a particular HA is dictated by its goals (such as the provision of medical assistance or support for children and elderly people), it is highly unlikely that, at least in the short term, there will be a significant reduction in the number of such organisations reacting to an event. Consequently, the challenge remains that of improving inter-agency cooperation and coordination so that 'the end beneficiary's requirements' are met more efficiently and effectively.

A key aspect of such an agenda is that of the management of the flow of information that is at the core of timely and effective logistic decision-making (Harrison and van Hoek, 2005; Christopher, 2011). Indeed, roughly 20 years ago, in one of the first academic papers on the subject of HL, Long and Wood (1995) suggested that the effectiveness of the information system is a principal determinant of the success of a humanitarian logistics supply chain. Subsequently, this view has been echoed by many other researchers, including Zhang, Zhou, and Nunamaker (2002), Maxwell and Watkins (2003), Maiers, Reynolds, and Haselkorn (2005), and Altay and Labonte (2014). The latter, in their analysis of the aftermath of the Haiti earthquake of 2010, clearly highlight the imperative of achieving effective humanitarian 
information management and exchange. Altay and Labonte (2014, p. 52) point out that it is 'not only a pre-requisite for all other flows in a humanitarian response, but it is also the principal source of all situational awareness, crisis decision making and coordination'.

Unfortunately, as noted in a recent analysis of Typhoon Haiyan, which struck the Philippines in November 2013, '[s]everal observations of previous complex disasters resurfaced: during the initial days of response, the lack of situational awareness . . . did not support the optimal use of resources, particularly in terms of logistics' (Center for Excellence in Disaster Management and Humanitarian Assistance, 2014, p. 7). The fundamental question that has yet to be answered satisfactorily, therefore, is: how can the development and maintenance of situational awareness be achieved in a fast-evolving environment that is populated by multiple players, and, hence, multiple supply networks?

\section{Study aim and methodology}

Clearly, HAs are not alone in confronting the challenge of developing and maintaining situational awareness. Indeed, in effect, any organisational construct that involves the integration of multiple data sources, especially those emanating from different organisational entities, will face a broadly similar challenge. Nevertheless, the defence forces of many countries have considered how best to develop a common understanding of multiple data feeds as a basis for action. Thus, given the relative immaturity of the HL field, there is perceived to be benefit in following the recommendation of Stock (1997) that logistics 'borrows' from other disciplines as a means of advancing knowledge and understanding.

Furthermore, given that the generic operating context of HAs in their response to a disaster/emergency and that of defence forces engaged in military activities have many similarities (Kovács and Tatham, 2009), the aim of this conceptual paper is to explore how the military/emergency services’ concept of a common operating picture (COP) can be adapted to the humanitarian setting.

In short, this paper contends that, from a supply chain management (SCM) perspective, the successful achievement of a humanitarian common logistic operating picture (H-CLOP) would be a cornerstone of a mechanism that captures, analyses, validates, distributes, and presents the real- or near real-time disposition of both existing and forecast demands, and the status and location of material in transit. This would, in turn, provide the basis for coordinated inter-agency logistic decision-making (Kapucu, 2006; Bharosa, Lee, and Janssen, 2009). In doing so, the study exposes, inevitably, the breadth and depth of the inter-agency coordination challenge. The goal, though, is to demonstrate the potential benefits of the proposed approach, 
and, hence, the efficiency and effectiveness gains that would accrue to HAs as well as to those affected by a particular disaster. The study does not pretend to offer a 'magic bullet' that will overcome institutional resistance to improved coordination, but, rather, seeks to show how such improved coordination, and its inherent advantages, could be achieved.

To fulfil the above objective, the next section of the paper explains the concept of an $\mathrm{H}$ CLOP in greater detail. This is followed by a discussion of the inter-agency coordination literature, after which the current status of emerging H-CLOP systems is outlined. The ways in which the residual challenges might be mitigated by the development of an H-CLOP concept are then discussed before a number of conclusions and recommendations for further research are offered.

It is stressed that, although the research is conceptual in nature, it is the product of a wide-ranging literature review that was designed to reveal the primary issues. The paper thereby draws on the existing humanitarian logistics literature and incorporates relevant elements of knowledge management theories to develop a high-level framework for the proposed H-CLOP.

A draft version of this paper was presented at the humanitarian logistics track of an academic conference on logistics to obtain the input of academics working in the field. This led to a broad discussion of the inter-agency coordination challenge and the means by which it might be overcome, within which there was broad support for the H-CLOP concept.

The importance of the research was also confirmed by the involvement of seven senior humanitarian logisticians based in Australia, the United Kingdom, and other parts of Europe. The point of distributing the amended paper was to explore their understanding of the $\mathrm{H}$ CLOP concept, its applicability, and practical implementation issues. In each case, a response was received that was supportive of the concept, while also indicating that inter-agency coordination remains one of the most challenging areas for the humanitarian community.

Following on from this initial indication of the relevance and significance of the topic, four more detailed, in-depth, face-to-face interviews were held with high-ranking humanitarian logistics practitioners. In each case, the interviewees reaffirmed the importance of the subject. More specifically, one of the interviewees indicated explicitly that there is growing interest within his organisation in building this next-generation capability, but that the principal challenge is perceived to be the identification of the types of information that would enable the HA to make SCM decisions.

The data were analysed in terms of the possibilities of developing a COP for humanitarian logistics, the potential enablers of such a development, and the challenges in 
such an undertaking. Results were discussed at a meeting with another constellation of four high-ranking humanitarian logisticians, in order to increase the confirmability and trustworthiness of the study.

\section{What is an H-CLOP?}

Comfort (2007, p. 191), writing in an emergency management context, suggests that the development of a COP implies 'achieving a sufficient level of shared information among the different organizations and jurisdictions participating in disaster operations at different locations, so all actors readily understand the constraints on each and the possible combinations of collaboration and support among them under a given set of conditions'. This is similar to the view of other commentators such as Copeland (2008) and Dickinson (2013) who suggest that a COP would be operationalised in the form of a pictorial representation of the relevant data as a means of supporting decision-making processes. Comfort (2007, p. 191), however, goes on to note that the delivery of the COP concept 'becomes more difficult as the size, scope, and severity of an impending disaster increase', and that it is complicated further by the involvement of organisations from the not-for-profit and the private sectors, in addition to more traditional responders.

The proposed H-CLOP, drawing on Comfort's objective for a COP, adopts the same perspective but is firmly focused on a subset of the whole disaster preparation and response challenge. The aim of the H-CLOP is to provide an enhanced means by which demand is balanced with supply through better understanding of the constraints and the possible levels of collaboration and support (Comfort, 2007), which, in turn, leads to improved decisionmaking at an individual organisation and collective level. In short, the ultimate goal of a fully operational H-CLOP is that of furnishing an overarching and, ideally, real time or near real time overview of the demand and supply situation as seen by the individual HAs, as well as at a cumulative level.

Significantly, this goal is similar to the approach found in a military context. The common logistic picture used by the UK's armed forces, for instance, is designed to deliver 'asset visibility' to the command, which, in turn, is defined as 'the real time disposition and status of assets, materiel in transit and forecast re-supply’ (Joint Doctrine and Concepts Centre, 2003, p. 3-7). Hence, the principal motivation of the paper is to explore the potential for the successful application of the latter approach in the former context.

\section{An overview of the inter-agency coordination literature}


Before embarking on an analysis of the literature, it is important to note that operations within the broad humanitarian field fall into two basic categories that reflect the presence or absence of a central player with the authority to direct the relief operation. Dolinskaya et al. (2011) describe them as 'centralised' and 'decentralised' approaches.

To date, the literature, particularly that related to a country's domestic environment in which the operations of various emergency response organisations, such as the ambulance, fire, police, and military services, are overseen by a unitary command structure, is focused almost entirely on the challenges inherent in centralised models—see, for example, the UK Integrated Emergency Management structure described by Salmon et al. (2011). By comparison, as Clarke (2013) points out, while inter-agency coordination of programming and policy has been much debated at the national, intergovernmental, and academic level, post-crisis and transitional operational coordination structures have remained weak, especially at the field level—a situation that is reflected in the unintegrated and frequently incoherent logistics activities of the multiple agencies that respond to a rapid-onset disaster or emergency (Tatham and Pettit, 2010). Importantly, the literature that discusses inter-organisational cooperation in a disaster/emergency context almost exclusively (either explicitly or implicitly) reflects a centralised model.

It is relevant to note, too, that, given the basic desire of all those responding to a disaster to support those affected, one might envisage that there would be a high level of inter-agency coordination. Sadly, however, generally this is not the case-not least because of the specific mandates that guide the actions of each agency, but also because, in reality, there is a significant amount of competition for donor and public funding. As the prestigious UK medical journal The Lancet (2010, p. 253) points out:

\footnotetext{
Large aid agencies and humanitarian organisations are often highly competitive with each other. Polluted by the internal power politics and the unsavoury characteristics seen in many big corporations, large aid agencies can be obsessed with raising money through their own appeal efforts. Media coverage as an end in itself is too often an aim of their activities. Marketing and branding have too high a profile. Perhaps worst of all, relief efforts in the field are sometimes competitive with little collaboration between agencies, including smaller, grass-roots charities that may have better networks in affected counties and so are well placed to immediately implement emergency relief.
}

One of the potential results of this pseudo-competitive environment is that, according to Bharosa, Lee, and Janssen (2009), relief workers are frequently more concerned with 
receiving information from other organisations than with providing information to those who may benefit.

Nevertheless, some coordination mechanisms do exist, with the most prominent being that developed across the UN family of agencies under the 'Clusters' concept. This approach groups together a broad range of preparation and response activities, such as camp management and coordination, emergency telecommunication, and logistics, with the World Food Programme (WFP) leading the latter (OCHA, 2012b). Importantly, according to Majewski et al. (2012, p. 6), 'no formal membership definition exists as the cluster has sought to remain open and not exclusive. Rather, Logistics Cluster participants are defined as organizations engaging at any point at global and/or country level in activities related to the Logistics Cluster'.

Nevertheless, and notwithstanding the UN's aspiration that the cluster system becomes the basis for coordination across the sector as a whole, the reality is that most HAs maintain a considerable degree of independence and only interface with the UN Logistics Cluster when the particular circumstances of the disaster response make this, in their eyes, the optimal course of action (Stoddard et al., 2007; Taff and Parry, 2010; Schuller, 2012). With these points in mind, a key focus of this research is the applicability of Dolinskaya et al. (2011)'s centralised approach described above to a decentralised context that is, to a greater or lesser extent, the reality on the ground.

More broadly, and as outlined in the introduction to this paper, the entire area of interagency coordination has been the subject of significant study, promoted not least by perceived failures following events such as the terrorist attacks in the US on 11 September 2001 (Dearstyne, 2006; Comfort and Kapucu, 2011), Hurricane Andrew in August 1992, the bombing of the Alfred P. Murrah Federal Building in Oklahoma City on 19 April 1995, and Hurricane Katrina in August 2005 (Donahue and Tuohy, 2006), and the Haiti earthquake in January 2010 (Vohr, 2011; Altay and Labonte, 2014). Drawing on prior research in organisational theory, the causes of mistakes made during the management of disasters have been analysed in significant detail (see, for example, Comfort 1999; Netten and van Someren, 2004; Comfort and Kapucu, 2006). In particular, the literature relating to complex adaptive systems, decision-making under conditions of uncertainty, socio-technical systems, and organisational adaptation has been used to help understand how to improve the behaviour of what Faraj and Xiao (2006, p. 1155) refer to as 'fast response organisations'. Furthermore, as Kapucu (2006, p. 210) notes, not only do emergencies create a high level of uncertainty and a 
need for timely and accurate information sharing, but 'the rate of decision making increases, particularly at the lower levels of organizations'.

Other contributions include those of Smith and Elliott (2007) who reflect on the barriers to organisational learning and the limited consideration that has been given to them, and of Kapucu et al. (2010) who discuss the potential benefits of mechanisms that enable individual organisations to fulfil their particular role and remit while, simultaneously, contributing to the macro-level response. Conversely, Berlin and Carlström (2011) probe the reasons why such inter-agency coordination is minimised at accident scenes and, in doing so, expose the differences between rhetoric and practice in a Swedish context. In the same vein, Salmon et al. (2011) examine the particular challenge of coordination between civil and military organisations and emphasise the importance of leadership, as well as the need for a clear understanding of the roles and responsibilities of the various agencies and of inter-agency information management and exchange.

At its core, the literature indicates that the coordination challenge is about the integration of organisational work under conditions of task interdependence and uncertainty (Comfort, 1999; Faraj and Xiao, 2006). From this, there stems a clear requirement for a mechanism to enable the seamless flow of information, and yet one that can adapt easily to change (Dorasamy, Raman, and Kalinnan, 2013). An acceptance of this proposition leads to discussion within the literature of the main requirements for such a system, including the need for standardisation of terminology and metrics, and of the inefficiencies caused by duplication of effort, reflecting poor coordination (Scott and Batchelor, 2013). Greater stress is also placed on the need for coordination in a decentralised environment (Ghadge, Hughes, and Albores, 2013), such as that relating to HL operations.

A further observation from the literature is the reflection that a COP (and, by implication, an H-CLOP) needs to go beyond the concept of a data warehouse, and move towards a situation in which the individual actors share their expertise and 'exchange ideas, learn from one another and make sense of each other's position and institutional background' (Wolbers and Boersma, 2013, p. 189). Although this approach is acknowledged and applauded, as will be discussed in the next section, the current status of emerging H-CLOP systems, together with the decentralised operational context, make this transition from a data warehouse to a true information management and decision-making system a major challenge.

At a more practical level, the importance of improved information management after a disaster is being increasingly recognised through, for instance, the UN's development of the concept of a Humanitarian Information Centre (HIC). This is a most valuable support 
mechanism, furnishing information such as the ' $3 \mathrm{~W}$ ' (Who? What? Where?) database, contact lists, maps, and meeting schedules (OCHA, 2014b), all of which are essential to the delivery of a more efficient response. At least in part, though, this HIC output can be characterised as providing 'standing' (or relatively slowly changing) data as distinct from that which would populate the H-CLOP, which aims to track a much more rapidly changing set of demands and responses. Furthermore, the HIC covers the UN's entire sphere of support interests (that is, the Clusters described above), whereas the H-CLOP is designed to concentrate on a particular subset of logistics.

\section{The current status of H-CLOPs}

It is recognised that capturing and disseminating the breadth and depth of data to satisfy the remit outlined above will be an extremely significant challenge, but the ultimate objective is that of a visual depiction of the affected area with a clear indication of the historic, current, and estimated demand, and the associated and planned movement of relief goods by the responding agencies. It is argued that, in this way, the potential for inter-agency gaps and overlaps will be reduced, and the consequential efficiency and effectiveness of the logistic decision-making process will be greatly improved. A further important benefit is that the associated data would be available to support the appropriate local authorities in taking full ownership of the recovery process.

Unsurprisingly, given the complexity of the challenge implicit in the above discussion, there has been limited progress to date. Bennett et al. (2006, p. 16), for instance, observed in the aftermath of the 2004 tsunami that ' $\mathrm{t}$ ] he issue of data analysis has confounded HIC from the outset - how to add value to an abundance of often contradictory data, and how to exclude sub-standard data'. Similarly, in a commentary on the Cyclone Nargis disaster in Myanmar in May 2008, Ramalingam and Pavanello (2008, p. 7) observed that, '[g]iven current knowledge gaps faced by operational agencies, collecting and synthesizing the different types of available information has the potential to make a crucial difference in the humanitarian performance'. Furthermore, in their analysis of the response to Typhoon Haiyan in November 2013, the Center for Excellence in Disaster Management and Humanitarian Assistance (2014, p. 24) noted that ' $[t]$ here was no common operating picture to assist in coordination of relief efforts'.

It is important to note, however, that the H-CLOP concept is not a new one. As discussed above, it reflects an approach that has been tried and tested within the armed forces of many countries, as well as within coalitions of nations, which need to coordinate their activities to ensure seamless military operations. At first sight it may appear surprising to 
draw on a military model for use in a humanitarian context, yet Kovács and Tatham (2009) have asserted that the basic operating environment following a natural disaster or a complex emergency is broadly similar: both reflect uncertain future events that entail the loss of physical and communications infrastructure, a potential breakdown in the rule of law, and multiple dead, injured, and/or traumatised people.

It is contended, therefore, that the cross-testing of models that have been shown to be effective in one environment is a sound approach. That said, it is acknowledged that the centralised military command-and-control hierarchy does not reflect that found in a typical HA, and this important distinction may, therefore, affect the efficacy of the use of common 'pictures' in disaster relief.

With this underpinning commonality in mind, it is unsurprising that a report by Vohr (2011) clearly demonstrates that US Marines responding to the 2010 Haiti earthquake attempted to develop an H-CLOP. Importantly, in reflecting after the event on the potential role of such an approach, Vohr (2011, p. 80) concludes that future operations will require a common understanding that 'should at minimum capture and display requirements, daily logistics activities, logistics centers, supply routes, medical centers, and engineering projects. It should be unclassified in a humanitarian assistance environment, allowing anyone to access the information with a few mouse clicks or key strokes'. In essence, therefore, Vohr (2011) considers that a H-CLOP concept is key to improving the HL response.

In parallel, several attempts have been made to develop a common logistics information technology (IT) system that can be used by multiple HAs, with one of the most recent being the HELIOS system created by the members of the Consortium of British Humanitarian Agencies. It is clear from the work of Blansjaar and van der Merwe (2011) that, in addition to providing a logistics information system tailored to the HL context, the core rationale for HELIOS was to achieve a commonality of processes and data definition standards across agencies. It was perceived that this would lead to a far greater level of integration in the HL community’s preparation for, and response to, a disaster or complex emergency.

Research by Scholten, Sharkey Scott, and Fynes (2010) indicates that the lack of integrated and IT systems is not the result of a lack of willingness or interest on the part of humanitarian logisticians. Rather, the overall reductions in available funding after the global financial crisis of 2007-08, together with the pressure applied by donors for funding to be used for 'direct aid' rather than support functions, conspire to constrain the ability of HAs to proceed down this route-notwithstanding the clear evidence from parallel commercial examples of the benefits of such investment. 
In a similar way, and reflecting its importance as a core component of the proposed $\mathrm{H}$ CLOP, other attempts have been and are being made to achieve a greater degree of standardisation across HAs. For instance, an evaluation of the needs assessment process following the 2004 tsunami reported that many of the shortcomings had been identified previously, including the slow compilation of such evaluations, leading to their obsolescence as a decision-making tool, and their inability to provide comprehensive coverage (de Ville de Goyet and Morinière, 2006). In this regard, and as exposed by Grant (2007), those conducting needs assessment activities use a plethora of agency-specific forms to capture the data. This finding is similar to that of Altay and Labonte (2014), who stated that decision-making was adversely affected by technical aspects such as accessibility, inconsistent formatting, and misaligned storage media. Both of these examples underscore the inefficiencies inherent in the HL system as a whole.

Furthermore, Grant (2007) found precious little agreement on the data to be collected or even the metrics to be used. This situation is similar to that identified by Telford and Cosgrove (2007), who suggest that multiple HAs conducted assessments after the 2004 tsunami, but that these were rarely shared-a point reiterated by Altay and Labonte (2014) in their discussion of the information management challenges during the response to the 2010 Haiti earthquake. However, recognising that the current system is sub-optimal, OCHA recently developed Operational Guidance on Coordinated Assessments in Humanitarian Crises, a Multi-Cluster/Sector Initial Rapid Assessment (MIRA) Manual, and a Humanitarian Dashboard, all of which are designed to facilitate the consolidation of needs assessment and response information, provide a structured format for the collection of data, and present a shared analysis of a humanitarian situation (OCHA, 2012c). Yet, the key issue remains that of obtaining broad agreement on and acceptance of this approach across all responding agencies and organisations in a decentralised decision-making environment.

A final observation in respect of this summary of the current situation is that, in part, the challenge of developing the H-CLOP concept is a reflection of the broader situation (outlined above) in which individual HAs are frequently in competition for scarce resources and funding (Kovács and Spens, 2011). Furthermore, it is clear that the absence of interorganisational coordination mechanisms results in a situation that is vastly different from that found in a 'for-profit' environment. In this latter context there is often a 'channel captain', such as the end retailer, who is able to enforce standards and modes of behaviour across the network as a whole. Thus, a major retailer such as WalMart in the US or Marks and Spencer 
in the UK will dictate the IT standards and associated processes with which suppliers must comply as a cost of doing business with them-in effect, achieving a centralised system.

\section{Challenges and potential solutions to the development of the H-CLOP concept}

Having introduced the H-CLOP concept, this section describes the four major components of a humanitarian supply network, each of which is then discussed in greater detail. First, the supply network must aim to satisfy the needs of those affected, which is the humanitarian equivalent of the demand component found in the 'for-profit' environment. Second, the response will draw on procurement activities both within and without the affected country. Third, there is a requirement for transport into and warehousing activities within the affected area. Fourth, final or 'last-mile' distribution takes place.

\section{Needs assessment}

There is a fundamental difference between 'for-profit' and HL supply networks. In the former case, individual customers generate demands, which, in turn, drive the supply network response via the selective purchase of goods from the end retailer. By contrast, in the HL case, those affected by a disaster may not be in a position to articulate their requirements, owing, for instance, to a disruption to the communications or physical infrastructure (Kovács and Spens, 2011). Other barriers include those pertaining to culture and language—in some communities, for example, it is inappropriate for a male to converse with a female outside of a family environment (Tatham and Kovács, 2010). Consequently, it is clear that the process of demand capture, or 'needs assessment' as it is referred to within the HL community, is considerably more challenging than that in the 'for-profit' environment.

\section{Procurement of relief items}

Although some relief goods may have been pre-positioned in facilities such as the UN's global system of warehouses, funding or other constraints may preclude procurement action until after the disaster has crystallised. The actual procurement source may be via a prenegotiated standing arrangement or from a local or regional entity that, to some small degree, will assist in rebuilding the local economy. In practice, and as part of their preparation for potential disasters, many agencies conduct a logistics capacity assessment (LCA) within a country or region, and these help to determine their high-level plan in response to a particular predicted disaster. However, as with other examples of a lack of cross-agency cooperation, such evaluations frequently are prepared independently and the results may not be shared 
subsequently. Clearly, this is an inefficient process and any system that delivers an H-CLOP needs to be able to incorporate the outcomes of such preparatory work, including clarifying the extent to which local resources can, indeed, respond to a disaster without leading to a major, demand-driven, hike in commodity prices (of food and fuel, for instance).

\section{Transport into and warehousing within the affected area}

The transport requirement will depend on the procurement source and may/may not require warehousing at various intermediate locations. This element of the overall process also includes the requirement to clear customs in a timely fashion. Once more, the LCA mechanism has the potential to provide the basic planning information, such as the intended role of the national and/or local government in the provision of transport assets, but, again, this should be incorporated on the basis of a shared understanding of such plans.

\section{'Last-mile’ distribution}

Final distribution, potentially the most challenging of the supply network elements, typically requires the logistician to overcome the impact of a degraded communications and physical infrastructure. It may also necessitate a different outcome from that forecast when the original needs assessment exercise took place. In other words, during the intervening period, demand and supply may have become unbalanced-be this in terms of quantity, specific commodities, and/or locations. In short, drawing on the preparatory work of the pan-agency LCAs, and in consultation with local governmental and community stakeholders, the aim here is to provide decision-makers with a comprehensive understanding of the physical infrastructure (bridges and roads, for example) and its availability for use as a transport medium.

\section{A summary of the data requirements for the proposed $\mathrm{H}$-CLOP}

Aggregating the requirements that are needed to deliver a comprehensive H-CLOP, it would need to capture, in an ideal world, data that cover:

- $\quad$ The type, volume, and location of relief goods required, as well as the places to which they need to be distributed and the associated time frames - that is, the demand side of the equation.

- $\quad$ The type, volume, and location of relief goods available both from outside the affected area and from local/regional sources, including the usability of the transport infrastructure, such as bridges, ports, railways, and roads. 
- The availability and mode of transport to the affected area, and the associated planned/scheduled arrivals of relief goods.

- Warehouse availability and usage, including that from governmental, HA, and private sector sources, both to and within the affected country.

- $\quad$ Transport availability and the means of making 'last-mile' distributions to recipients, including, where possible, assets available from the affected communities, noting that, if payment is required, this could be 'in-kind'.

- $\quad$ Any special handling requirements, such as the need for 'cold chains' to support the movement of certain medicines.

Given the breadth of the data requirements summarised above, it is clear that the management of the associated information as a basis for inter-agency decision-making will be considerable. In this regard, the basic requirements that underpin the development of the $\mathrm{H}$ CLOP concept are no different to a similar endeavour in a 'for-profit' supply network, in which an overarching system provides end-to-end visibility of demand and supply data. Indeed, in one sense, the challenge may be less demanding as the number of stock keeping units (SKUs) involved is significantly less. For instance, the catalogue of the International Federation of Red Cross and Red Crescent Societies (IFRC) contains some 10,000 items within three volumes, but of these, two are devoted to medical equipment. Thus, the non-food item (NFI) range is of the order of 3,000 SKUs, which can be compared to a typical supermarket that will manage approximately 40-45,000 SKUs (Ellickson, 2011).

As outlined above, though, and as is discussed in greater detail below, there are a number of other challenging features, including the sheer number of individual entities operating within the network, the lack of standardisation, and the requirement for the network be able to be assembled at extremely short notice in an international and cross-cultural environment. Nevertheless, it is argued that many of the core challenges inherent in the development and implementation of an H-CLOP can be understood from the perspective of information management. The next section of the paper outlines the key issues from this standpoint.

\section{Information management}

It is important to begin by recognising that there is a hierarchy of increasing complexity that runs from 'data' through to 'knowledge', and, ultimately, to 'wisdom' (see, for example, 
Tobin, 1996; Gamble and Blackwell, 2001). Within this hierarchy, this paper concentrates on the challenges to the development of an H-CLOP as a pre-cursor to the management of knowledge, and, in particular, 'explicit knowledge', as a basis for improved decision-making. By the same token, the associated management function, while variously defined, is generally seen as a strategy to collect, store, and retrieve knowledge in a systematic way, and then distribute the results to those who need them in a timely manner.

As such, a knowledge management system must provide a mechanism that will:

- $\quad$ capture;

- $\quad$ analyse and filter;

- $\quad$ index, organise, and remove redundancies; and

- $\quad$ make available and judge (Gamble and Blackwell, 2001; King, 2005; de Vasconcelos et al., 2005).

Importantly, these core requirements have not changed with the advent of increasing access to social media and mobile information technologies. Indeed, as made plain in a report by the Harvard Humanitarian Initiative (2011) that considers recent developments in the humanitarian communications field, the presence of multiple additional contributors to the information management challenge is creating a new level of complexity for decision-makers.

Before discussing these component activities in detail in the context of an H-CLOP, it is useful to make some general observations on information management challenges. First, a principal thread running through many, if not all, knowledge management activities is that of developing and establishing commonality of processes and procedures across multiple agencies. This does not mean necessarily replication of, say, IT systems-although this would unquestionably ease the data exchange problem significantly—but, as noted by Day, Junlas, and Silva (2009), it does necessitate a seamless inter-system exchange of data.

At first sight this may appear a major challenge to the HA community, which is composed of multiple independent entities, but an initial review of the IFRC, Oxfam, and World Vision equipment catalogues indicates that most commodities are described by a dataset of some 12 fields. Furthermore, while the full range of commodities within the NFI range has been estimated at roughly 3,000 SKUs (see above), Everywhere, Jahre, and Navangul (2011) have demonstrated that only a subset of these were employed in the majority 
of responses. Hence, although the breadth of the data exchange problem is not trivial, it is arguably solvable if agencies were prepared to 'grasp this nettle'.

In parallel, the example of the HELIOS system (see above) is pertinent. This project, originally supported by the US-based Fritz Institute, has led to three major HAs (International Medical Corps, Oxfam GB, and World Vision International) collaborating in the development of a common logistics management software package (Blansjaar and van der Merwe, 2011). Consequently, from a purely technical perspective, the achievement of inter-agency data exchange would appear to be entirely feasible.

Indeed, the benefits of a standardised structure for humanitarian coordination and information sharing to meet the agencies' respective and common requirements has been recognised for more than a decade (United States Institute of Peace, 2000). Yet, the critical issue of persuading multiple independent agencies that such cooperation is necessary and appropriate remains a major stumbling block (Day, Junlas, and Silva, 2009)—a point considered further in the concluding section.

Second, the transient nature of the logistics community militates against organisational learning - as seen in many recent major disasters. What is more, Telford and Cosgrove (2007), for instance, underline the limited surge capacity of many HAs and the overall shortage of appropriately experienced personnel who can operate in an emergency at an international level. Furthermore, as discussed above, Thomas and Mizushima (2005) estimate that many individuals working in HAs remain in their jobs for less than two years.

As an example of the consequences of this, the deployment of the UN Joint Logistics Centre to support the response to Cyclone Nargis in Myanmar in 2008 included secondees from nine different organisations (United Nations Joint Logistics Centre, 2008). This core point is reinforced by the research of Altay and Labonte (2014), who contrast the permeability of UN agencies and HAs. The concept of permeability refers to the flow of people and information across organisational boundaries, with HAs reflecting permeability. As a result, there is an adverse impact on organisational learning and institutional memory within such entities. Thus, in addition to the technological and process challenges implicit in the development of an H-CLOP, there is also a clear requirement for an ongoing programme of training at the international and national level. Without this investment in the people dimension, the whole project has the potential to become an expensive 'white elephant'.

Third, the system needs to be both flexible and scalable. For example, the data needed to support the logistics response in a small Pacific Island nation will be markedly different from that required in a large developed/industrialised country. There is obviously a subtle and 
important balance to be struck here between ensuring conformity with common processesnot least as a means of reducing the training burden — and of providing sufficient flexibility to ensure fitness-for-purpose in the specific operational context. Clearly, an appropriately sized training programme will be an essential component of the proposed system.

Fourth, the core steps outlined below remain key, notwithstanding the development of new data sources and technological approaches such as CrisisMappers, OpenStreetMap, Sahana Software Foundation, and Ushahidi.

\section{Data capture}

Now, turning to the fundamental components of an information management system as listed above, in respect of the demand side of the challenge (that is, the needs assessment process), the primary issue here is the physical capture of data. This will usually require input from regions in which the communication links, to the extent that they existed prior to the disaster, are likely to be severely degraded and/or destroyed. However, advances in technology have the potential to speed up this process, such as data transmission via satellite telephones using pre-designed forms.

Importantly, though, data capture should be based on a common format, rather than, as is currently the case, each agency using a different form to collect what is essentially the same information. Much work to develop such a common format and associated definitions and explanations has been done by the Needs Assessment Task Force of the UN Inter-Agency Standing Committee, ${ }^{1}$ and this is believed to represent a good starting point for further evaluation. Undoubtedly, to be successful, the needs assessment process cannot and must not rely purely on the activities of international agencies. Instead, those working in the affected country, be they governmental employees or members of HAs, should be trained to use the needs assessment forms and the associated data transfer mechanisms. Indeed, given that all agencies require the permission of the host government to operate in a country, there is potentially an opportunity to mandate adherence to certain procedures, such as the use of a common needs assessment form, as a condition of entry.

This observation plainly points up the important topic of the setting of, and adherence to, standards that is very much the subject of current debate by the Joint Standards Initiative, which has the support of a number of major bodies including the Humanitarian

\footnotetext{
${ }^{1}$ For more information, see http://www.humanitarianinfo.org/iasc/pageloader.aspx?page=content-subsidi-common-

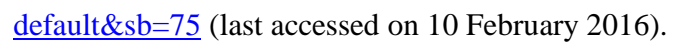


Accountability Partnership, People in Aid, and The Sphere Project (Austin and O’Neill, 2013). A full discussion of this issue is beyond the scope of this paper, but it is suggested that a potential model is that of the International Search and Rescue Advisory Group (INSARAG) and the Foreign Medical Teams (FMTs) (Norton et al., 2013). Both of these set specific standards for individuals and organisations, which, in turn, accord the government of an affected country the opportunity to reject assistance from those who are not recognised members of INSARAG or the FMTs.

Turning to the supply side, it will be necessary to develop appropriate linkages to the $\mathrm{H}$ CLOP that will enable the monitoring of planned and actual movements of relief goods. This would require national and international agencies agreeing to share the required data in order to paint a composite, time-sensitive, picture of the physical movement of the relief goods. In the same way as for the demand side, there may well also be a role for the host nation: to demand commonality of standards and approaches, and, even, to provide some of the coordination mechanisms through its disaster management organisation.

It is fully accepted that this requirement presents a challenge on two levels. First, many HAs struggle to achieve the desired end-to-end visibility of their supply network, and certainly this does not happen in real time. However, the advent of improved track-and-trace systems integrated into mobile telephone and messaging technologies and the growth in mobile telephone/internet coverage is leading to a greater level of assurance in this respect. Second, as discussed earlier, the existence of the required technical capability does not, of itself, lead to the seamless exchange of data that is implicit in a fully-functioning H-CLOPthis will require a change of approach within the HA community.

One of the particular challenges in relation to both the demand and the supply side is perceived to be that of not just capturing and abstracting the data from those informants who are part of an organised construct, such as local HA representatives, but also achieving this vis-à-vis the myriad ad hoc groups that, inevitably, will surface. The earthquakes in Christchurch, New Zealand in 2011 and 2012, for instance, spawned disasters of such magnitude that, even in a developed country, the national, local, and international responders were unable to meet the needs of the affected population. Consequently, ad hoc groups, such as the 'mud army', frequently led in the development of logistic 'micro operations'. These were typically created, managed, and operated by the residents of a particular geographical area, and some incorporated catering, road transport (all-terrain vehicles), and even helicopters. As before, the issue here is that of developing a mechanism to integrate, but not constrain, the information on their activities so that a comprehensive H-CLOP materialises. 


\section{Analyse and filter}

Inevitably, both the demand (needs assessment) and supply data will, to an extent at least, contain errors. In the case of the demand side, these errors may be the product of physical and communications disruptions that will result in delays in the assessment data (who?/what?/where?) reaching the H-CLOP. In the case of the supply side, similar delays in confirming the location of material moving through the supply network are, to a degree, likely. At least in the first instance, there is probably little that can be suggested to overcome the humanitarian equivalent of the 'fog of war' in the early stages of the response to a disaster. That said, there is arguably scope for those with local knowledge and expertise to serve as 'sanity checkers', and, potentially, using a multiplicity of local networks, to weed out data that are clearly incorrect.

As a parallel approach to overcoming this challenge, Altay and Pal (2014) recommend that the leads for each of the UN Clusters assume the part of information broker or facilitator across the relevant segment of the response. Critically, Altay and Pal (2014, p. 12) indicate that this approach will be successful only if HAs 'are willing to share quality information and the cluster leads act as a filter’.

\section{Index, organise, and remove redundancies}

As part of the analytical process, it will be necessary to develop an appropriate construct that organises the data in a way that is logical to users. In terms of the demand side, it is suggested that, as discussed above, this is likely to reflect the various dimensions of a common needs assessment form, with an overlay that relates to the specific geographical location and the timing of the report. Here, it will be important also to ensure an appropriate interface with pre-existing research, such as the country-specific LCAs, which, in turn, should reflect information sourced from the local population and community organisations. Similarly, it is suggested that the supply-side processes will reflect the movement of material along the supply network using a common format based on a common dataset. This will also need to be integrated into movement information that updates the location of a particular consignment at a particular moment in time.

\section{Make available and judge}

The principal challenge here is that of integrating the demand- and supply-side data in such a way that the major issues are easily extracted and highlighted. This is likely to involve the use 
of some form of geographically-based visual interface that can be made available to multiple authorised users (that is, the HAs) using open-source software. In this respect, there is likely to be a requirement to establish a connection with those organisations that are able to provide real-time geospatial information, such as the United Nations Office for Outer Space Affairs (UNOOSA), via the UN-SPIDER programme that seeks to deliver space-based information for disaster management and emergency response. It may be appropriate, too, to establish linkages with the UN/European Union (EU) Global Disaster Alert and Coordination System (GDACS). ${ }^{2}$ GDACS provides the international disaster response community with near realtime alerts on natural disasters around the world and with tools to facilitate response coordination.

The ultimate aim of the H-CLOP concept is to paint a comprehensive, valid, up-to-date, and easily understood 'picture' of the logistic response to the disaster in question as a basis for improved decision-making. While the achievement of an H-CLOP may do much to ensure the accuracy and timeliness of the data on which decisions can be made, there is an implicit requirement for a more effective decision-making process that will be able to react efficiently and effectively to the emerging logistic picture. Arguably, this implies moving to a centralised system, but this aspect of the problem goes beyond the scope of this paper. Nevertheless, it represents a primary challenge that the HL community as a whole will need to face.

In summary, there is no doubt that the information management challenges pertaining to the H-CLOP concept are significant. Yet, similarly complex challenges have been overcome in other contexts. This fact alone, therefore, should not serve as an excuse for inactivity and the consequential inefficiency of the supply networks.

\section{Concluding remarks and scope for further research}

This conceptual paper has been developed from a broad range of literature and supplemented by insights and advice from academics working in the field and a number of senior humanitarian logistics practitioners. It is clear, though, that the assumptions and resultant conclusions need to be tested in a formal way with relevant key informants from a whole spectrum of agencies and associated organisations. To achieve this, an appropriate approach could well be that of taking the outlined theoretical concept and comparing it with the existing and planned logistics systems that deliver some elements of the H-CLOP concept, such as those currently in use by UN agencies, other HAs, the armed forces and emergency services

\footnotetext{
${ }^{2}$ For more information, see http://portal.gdacs.org/about (last accessed on 10 February 2016).
} 
of apposite countries, and relevant private sector companies operating in the procurement, transportation, and storage fields.

These theoretical and practical perspectives can then be analysed, and, subsequently, the proposed high-level approach to the development of H-CLOP can be tested. In doing so, it is likely that a clear understanding of the context will be a fundamental aspect. For instance, the methodologies and procedures that are suitable may well prove to be different following a crisis in a developed country (such as in the aftermath of the Christchurch, New Zealand, earthquakes as compared to that in Haiti). In addition, this analysis would provide an indication of the gap that would need to be bridged between existing organisational-level systems and the proposed global approach. As part of this process, it is anticipated that the resulting construct would be tested against a number of representative scenarios (see, for example, Tatham et al., 2013).

The overall aim of this paper was to explore how the military/emergency services' concept of a COP can be adapted to the humanitarian context. Via this process, the ultimate goal is to provide those engaged in the delivery of logistic support after a disaster or complex emergency with a shared awareness of the current and emerging response. Subsequent implementation of this vision would improve the ability of decision-makers to react to unfolding circumstances in a timely, efficient, and effective way. In doing so, it is recognised that the above research project would represent but a partial response to the coordination challenge, and that further investigations into the optimal decision-making process will be required.

Given the frequency with which inter-agency coordination is cited as a major obstacle to an efficient and effective humanitarian logistic response, this paper has outlined one way in which it may be mitigated by the provision of a decision-making aid. Undoubtedly, the HCLOP would not, of itself, overcome the requirement for improved inter-agency coordination, but it is believed that it would provide a means by which the impacts of prospective decisions can be exposed more clearly.

There is no denying the enormity of the change implied by the development of an $\mathrm{H}$ CLOP in which information is shared and the resultant inter-agency gaps and overlaps are reduced. Arguably of even greater importance, however, would be the ability of the H-CLOP to establish linkages with national disaster management systems so that the response is more clearly and easily overseen by the affected country.

Equally important, and as highlighted in the earlier discussion on the current status of H-CLOP systems, those that have proved to be effective are clearly structured around the 
centralised model of Dolinskaya et al. (2011). Examples include those found within the military forces of many nations as well as the tried and tested processes of INSARAG, as documented in its guidelines and methodology (INSARAG, 2012). Indeed, the developing literature on the use of FMTs has reached a similar conclusion (Aitken et al., 2012; Norton et al., 2013).

A clear implication of this situation is that the information management problem would be managed best by a centralised structure. A main conclusion of this research is that every effort should be made to achieve a mechanism that allows such an approach to be developed. Indeed, in the absence of such a mechanism that, to a greater or lesser extent, would lead to some degree of compulsion, there is a clear possibility that even the most committed of HAs will give insufficient weight to the voluntary population of the proposed H-CLOP concept.

Interestingly, there are frequent and repeated calls for greater coordination of the relief effort and/or cooperation among HAs. Consequently, this research will inevitably move into the difficult and complex area of inter-HA and UN-HA relations (Whiting and Ayala-Öström, 2007). In this respect, the development of international air travel after the Second World War may serve as an historical parallel with which to inform this debate. Under the overall direction of the International Civil Aviation Organization (ICAO), a common set of standards covering areas such as air traffic control, aircraft maintenance, and pilot training have been developed to which individual airlines must adhere. A similar model could be developed for the humanitarian logistics sector.

Nevertheless, given the unquestionable benefits of improved information management to the efficient and effective operation of humanitarian logistics, it is hoped that the intrinsic merit of the H-CLOP concept will help lead to its development and application. In parallel, it is hoped also that the necessary management structures will grow with the all-important support of the user community. The research described in this paper may be seen, therefore, as one small element of what Solomon and Brown (2004, p. 3) describe as 'creating conditions that enable separate organizations to share information toward a common end'.

\section{Correspondence}

Peter Tatham, Department of International Business and Asian Studies, Griffith Business School, QLD 4222, Gold Coast, Australia. Telephone: +61 (0)7 555 28490; e-mail: p.tatham@griffith.edu.au

\section{References}


Aitken, P. et al. (2012) 'Leadership and use of standards by Australian disaster medical assistance teams: results of a national survey of team members'. Prehospital and Disaster Medicine. 27(2). pp. 142-147.

Altay, N. and M. Labonte (2014) 'Challenges in humanitarian information management and exchange: evidence from Haiti'. Disasters. 39(1). pp. 50-72.

Altay, N. and R. Pal (2014) 'Information diffusion among agents: implications for humanitarian operations’. Production and Operations Management. 23(6). pp. 10151027.

Austin, L. and G. O’Neil (2013) The Joint Standards Initiative Global Stakeholder Consultation Report. April. http://pool.fruitycms.com/humanitarianstandards/News/FINAL-JSI-StakeholderConsultation-Report.pdf (last accessed on 10 February 2016).

Bennett, J.W., C. Bertrand, C. Harkin, S. Samarasinghe, and H. Wickramatillake (2006) Coordination of International Humanitarian Assistance in Tsunami-affected Countries. July. Tsunami Evaluation Coalition, London. http://www.alnap.org/pool/files/coordination-final-report.pdf (last accessed on 10 February 2016).

Berlin, J.M. and E.D. Carlström (2011) 'Why is collaboration minimised at the accident scene?’. Disaster Prevention and Management. 20(2). pp. 159-171.

Bharosa, N., J.K. Lee, and M. Janssen (2009) 'Challenges and obstacles in sharing and coordinating information during multi-agency disaster response: propositions from field exercises’. Information Systems Frontiers. 12(1). pp. 49-65.

Blansjaar, M. and C. van der Merwe (2011) 'The importance of information technology in humanitarian supply chains: opportunities and challenges in the HELIOS project'. In M.G. Christopher and P.H. Tatham (eds.) Humanitarian Logistics: Meeting the Challenge of Preparing for and Responding to Disasters. Kogan Page, London. pp. 4763.

Center for Excellence in Disaster Management and Humanitarian Assistance (2014) Lessons from Civil-Military Disaster Management and Humanitarian Response to Typhoon Haiyan (Yolanda). January. Joint Base Pearl Harbor-Hickam, Hawaii. http://startides.net/sites/default/files/documents/files/CFE_Lessons\%20from\%20Typhoon\%20Hai yan.pdf (last accessed on 10 February 2016).

Christopher, M.G. (1992) Logistics and Supply Chain Management: Strategies for Reducing Costs and Improving Services. Pitman Publishing, London. 
Christopher, M.G. (2011) Logistics and Supply Chain Management. Fourth edition. Pearson Education Limited, Harlow.

Clarke, J.N. (2013) 'Transitional coordination in Sudan (2006-08): lessons from the United Nations Resident Coordinator’s Office’. Disasters. 37(3). pp. 420-441.

Comfort, L.K. (1999) Shared Risk: Complex Systems in Seismic Response. Pergamon Press, Oxford.

Comfort, L.K. (2007) 'Crisis management in hindsight: cognition, communication, coordination and control’. Public Administration Review. 67(S1). pp. 189-197.

Comfort, L.K. and N. Kapucu (2006) 'Inter-organizational coordination in extreme events: the World Trade Center attacks, September 11, 2001’. Natural Hazards. 39(2). pp. 309327.

Copeland, J. (2008) Emergency Response: Unity of Effort through a Common Operational Picture. Strategy Research Project. US Army War College, Carlisle Barracks, PA.

Day, J.M., I. Junlas, and L. Silva (2009) 'Information flow impediments in disaster relief supply chains'. Journal of the Association for Information Systems. 10(8). pp. 637-660.

de Vasconcelos, J.B., P.C. Seixtas, P.G. Lemos, and C. Kimble (2005) ‘Knowledge management in non-governmental organisations'. Paper presented at the 7th International Conference on Enterprise Information Systems, Miami, FL, US, 24-28 May 2005.

de Ville de Goyet, C. and L. Morinière (2006) The Role of Needs Assessment in the Tsunami Response. July. Tsunami Evaluation Coalition, London. http://www.alnap.org/resource/3531 (last accessed on 10 February 2016).

Dearstyne, B. (2006) 'The FDNY on 9/11: information and decision making in crisis'. Government Information Quarterly. 24(1). pp. 29-46.

Dickinson, I.F.G. (2013) National Resilience Extranet Common Operating Picture. Niteworks Document NW/Pj/ResComms/4902a.

https://www.gov.uk/government/uploads/system/uploads/attachment_data/file/79250/N ational_Resilience_Extranet_Common_Operating_Picture_v1_1_report_0.pdf (last accessed on 10 February 2016).

Dolinskaya, I.S., Z.S Sh, K.R. Smilowitz, and M. Ross (2011) 'Decentralized approaches to logistics coordination in humanitarian relief'. In T. Doolen and E. Van Aken (eds.) Proceedings of the 2011 Industrial Engineering Research Conference. http://www.google.fi/url?sa=t\&rct=j\&q=\&esrc=s\&source=web\&cd=7\&ved=0CFQQFj AG\&url=http\%3A\%2F\%2Fhl.mccormick.northwestern.edu\%2Fpublications\%2FIERC2 
011_HLCoordination2011_Final.pdf\&ei=x77KUfnHBoeXtQaWp4DABA\&usg=AFQj CNEZPI36K1fcw8eDVInCczYPZlxwKw\&sig2=GFyrROO0uOb4ikV8llRHaA (last accessed on 10 February 2016).

Donahue, A.K. and R.V. Tuohy (2006) 'Lessons we don’t learn: a study of the lessons of disasters, why we repeat them, and how we can learn them'. Homeland Security Affairs. II(2). pp. 1-28.

Dorasamy, M., M. Raman, and M. Kalinnan (2103) 'Knowledge management systems in support of disaster management: a two decade review’. Technological Forecasting and Social Change. 80(9). pp. 1834-1853.

Ellickson, P.B. (2011) 'The evolution of the supermarket industry: from A\&P to Wal-Mart'. 15 March. http://paulellickson.com/SMEvolution.pdf (last accessed on 10 February 2016).

Everywhere, M. Jahre, and K.A. Navangul (2011) 'Predicting the unpredictable - demand forecasting in international humanitarian response'. Paper presented at the 23rd Annual NOFOMA (Nordic Logistics Research Network) Conference, Harstad, Norway, 9-10 June 2011.

Faraj, S. and Y. Xiao (2006) 'Coordination in fast-response organizations'. Management Science. 52(8). pp. 1155-1167.

Gamble, P.R. and J. Blackwell (2001) Knowledge Management. Kogan Page, London. Ghadge, A., K. Hughes, and P. Albores (2013) 'Disaster risk management: ICT based approach’. Paper presented at the 18th Logistics Research Network Annual Conference, Birmingham, UK, 4-6 September 2013.

Grant, K.S. (2007) ‘Standardising logistics needs assessments for use in emergencies’. In Tatham, P.H. (ed.) Proceedings of the 1st Cardiff/Cranfield International Humanitarian Logistics Symposium. Cranfield University, Shrivenham, pp. 12-20.

Harrison, A. and R. van Hoek (2005) Logistics Management and Strategy. Second edition. Pearson Education Limited, Harlow.

Harvard Humanitarian Initiative (2011) Disaster Relief 2.0: The Future of Information Sharing in Humanitarian Emergencies. United Nations Foundation, Washington, DC, and Vodafone Foundation, London. http://www.unfoundation.org/assets/pdf/disasterrelief-20-the.pdf (last accessed on 10 February 2016).

Joint Doctrine and Concepts Centre (2003) Logistics for Joint Operations. Joint Warfare Publication 4-00. Second edition. Joint Doctrine and Concepts Centre, Shrivenham. http://ids.nic.in/UK\%20Doctrine/UK\%20(11).pdf (last accessed on 10 February 2016). 
Kapucu, N. (2006) ‘Interagency communication networks during emergencies’. American Review of Public Administration. 36(3). pp. 207-225.

Kapucu, N., T. Arslan, and F. Demiroz (2010) 'Collaborative emergency management and national emergency management network’. Disaster Prevention and Management. 19(4). pp. 452-468.

King, D.J. (2005) 'Humanitarian Knowledge Management’. https://hiu.state.gov/Products/Worldwide_HumanitarianKnowledgeManagement_2005 Apr_HIU.pdf (last accessed on 10 February 2016).

Kovács, G. and K.M. Spens (2011) 'Trends and developments in humanitarian logistics - a gap analysis’. International Journal of Physical Logistics and Distribution Management. 40(1). pp. 32-45.

Kovács, G. and P.H. Tatham (2009) 'Responding to disruptions in the supply network - from dormant to action'. Journal of Business Logistics. 30(2). pp. 215-229.

Leiras, A. et al. (2014) 'Literature review of humanitarian logistics research: trends and challenges’. Journal of Humanitarian Logistics and Supply Chain Management. 4(1). pp. 95-130.

Long, D.C. and D.R. Wood (1995) 'The logistics of famine relief'. Journal of Business Logistics. 16(1). pp. 213-229.

Maiers, C., M. Reynolds, and M. Haselkorn (2005) 'Challenges to effective information and communication systems in humanitarian relief organizations'. Paper presented at the IEEE Professional Communication Conference, Limerick, Ireland, 10-13 July 2005.

Majewski, B., P. Boulet-Desbareau, M. Slezak, F. De Meulder, and K. Wilson (2012) Joint Evaluation of the Global Logistics Cluster. Volume I - Full Report. Report number: 0E/2012/006.

http://documents.wfp.org/stellent/groups/public/documents/reports/wfp251775.pdf (last accessed on 10 February 2016).

Maxwell, D. and B. Watkins (2003) 'Humanitarian information systems and emergencies in the Greater Horn of Africa: logical components and logical linkages’. Disasters. 27(1). pp. 72-90.

Netten, N. and M. van Somerem (2011) 'Improving communication in crisis management by evaluating relevance of messages'. Journal of Contingencies and Crisis Management. 19(2). pp. 75-85.

Norton, I., J. von Schreeb, P. Aitken, P. Herard, and C. Lajolo (2013) Classification and Minimum Standards for Foreign Medical Teams in Sudden Onset Disasters. World 
Health Organization, Geneva.

http://www.who.int/hac/global_health_cluster/fmt_guidelines_september2013.pdf (last accessed on 10 February 2016).

OCHA (Office for the Coordination of Humanitarian Affairs) (2012a) OCHA Message:

Humanitarian Principles. OCHA, New York, NY.

https://docs.unocha.org/sites/dms/Documents/OOM-

humanitarianprinciples_eng_June12.pdf (last accessed on 10 February 2016).

OCHA (2012b) ‘Cluster coordination’. http://www.unocha.org/what-we-do/coordinationtools/cluster-coordination (last accessed on 10 February 2016)

OCHA (2012c) 'Coordination tools: needs assessment’. http://www.unocha.org/what-wedo/coordination-tools/needs-assessment (last accessed on 10 February 2016).

OCHA (2014a) Coordination to Save Lives: History and Emerging Challenges. OCHA, New York, NY.

https://docs.unocha.org/sites/dms/Documents/Coordination\%20to\%20Save\%20Lives\% 20History\%20and\%20Emerging\%20Challenges.pdf (last accessed on 10 February 2016).

OCHA (2014b) 'Information management'. http://www.unocha.org/what-we-do/informationmanagement/overview (last accessed on 10 February 2016).

Ramalingam, B. and A. Pavanello (2008) Cyclone Nargis: Lessons for Operational Agencies. Active Learning Network for Accountability and Performance, London.

http://www.alnap.org/pool/files/ALNAPLessonsCycloneNargis.pdf (last accessed on 10 February 2016).

Salmon, P., N. Stanton, D. Jenkins, and G. Walker (2011) 'Coordination during multi-agency emergency response: issues and solutions’. Disaster Prevention and Management. 20(2). pp. 140-158.

Scholten, K., P. Sharkey Scott, and B. Fynes (2010) '(Le)agility in humanitarian aid (NGO) supply chains'. International Journal of Physical Distribution and Supply Chain Management. 40(8-9). pp. 623-635.

Schuller, M. (2012) Killing with Kindness: Haiti, International Aid, and NGOs. Rutgers University Press, New Brunswick, NJ.

Scott, N. and S. Batchelor (2013) 'Real time monitoring in disasters'. IDS Bulletin. 44(2). pp. $122-134$.

Smith, D. and D. Elliott (2007) 'Exploring the barriers to learning from a crisis'. Management Learning. 38(5). pp. 519-538. 
Solomon, R. and S. Brown (2004) 'Creating a common communications culture: interoperability in crisis management'. Virtual Diplomacy Series. No. 17. United States Institute of Peace, Washington, DC. http://www.usip.org/publications/creatingcommon-communications-culture-interoperability-in-crisis-management (last accessed on 10 February 2016).

Stock, J.R. (1997) 'Applying theories from other disciplines to logistics’. International Journal of Physical Distribution and Logistics Management. 27(9-10). pp. 515-539.

Stoddard, A., A. Harmer, K. Haver, D. Salomons, and V. Wheeler (2007) Cluster Approach Evaluation. November.

http://www.humanitarianoutcomes.org/sites/default/files/pdf/ClusterApproachEvaluatio n.pdf (last accessed on 10 February 2016).

Taff, M. and E. Parry (2010) 'Haiti: still trapped in the emergency phase'. http://www.haitilibre.com/en/news-1384-haiti-social-still-trapped-in-the-emergencyphase.html (last accessed on 10 February 2016).

Tatham, P.H. and G. Kovács (2010) 'The impact of gender on humanitarian logistics’. International Journal of Mass Emergencies and Disasters. 28(2). pp. 148-169.

Tatham, P.H. and K.M. Spens (2009) 'Towards a humanitarian logistics knowledge management system’. Disaster Prevention and Management. 20(1). pp. 6-26.

Tatham, P.H. and S.J. Pettit (2010) 'Transforming humanitarian logistics: the journey to supply network management’. International Journal of Physical Distribution and Logistics Management. 40(8-9). pp. 609-622.

Tatham, P.H., C. L’Hermitte, K. Spens, and G. Kovács (2013) ‘Humanitarian logistics: development of an improved disaster classification framework'. Paper presented at the 11th ANZAM (Australia and New Zealand Academy of Management) Operations, Supply Chain, and Services Management Symposium, Brisbane, Queensland, Australia, 20-21 June 2013.

Telford, J. and J. Cosgrove (2007) 'The international humanitarian systems and the 2004 Indian Ocean earthquake and tsunamis’. Disasters. 31(1). p. 1-28.

The Lancet (2010) 'Growth of aid and the decline of humanitarianism'. The Lancet. 375(9711). p. 253.

Thomas, A. and M. Mizushima (2005) ‘Logistics training: necessity or luxury?’. Forced Migration Review. 22. pp. 60-61.

Tobin, D. (1996) Transformational Learning: Renewing your Company through Knowledge and Skills. John Wiley and Sons, New York, NY. 
United States Institute of Peace (2000) 'Taking it to the next level: civilian-military cooperation in complex emergencies'. Virtual Diplomacy Series. No. 10. United States Institute of Peace, Washington, DC. http://webharvest.gov/peth04/20041021144750/http://www.usip.org/virtualdiplomacy/p ublications/reports/NextLevel.pdf (last accessed on 10 February 2016).

United Nations Joint Logistics Centre (2008) Logistics Cluster Myanmar: Cyclone Nargis, $10^{\text {th }}$ May-10 $10^{\text {th }}$ August 2008, End of Mission Report. http://www.logcluster.org/sites/default/files/documents/LogsCluster_MMR_EndofMissi onReportE\%2520_080810.pdf (last accessed on 10 February 2016).

Vohr, J.A. (2011) 'Haiti disaster relief: logistics is the operation'. Military Review. JulyAugust. pp. 76-82.

Völz, C. (2005) 'Humanitarian coordination in Indonesia: an NGO viewpoint'. Forced Migration Review. Special Issue. July. pp. 26-27.

Whiting, M. and B. Ayala-Öström (2007) 'Humanitarian logistics: a perspective on the dominance of humanitarian logistics by the UN'. In P.H. Tatham (ed.) Proceedings of the 1st Cardiff/Cranfield International Humanitarian Logistics Symposium. Cranfield University, Shrivenham. pp. 57-63

Wolbers, J. and K. Boersma (2013) 'The common operational picture as collective sensemaking’. Journal of Contingencies and Crisis Management. 21(4). pp. 186-199. Zhang, D., L. Zhou, and J.F. Nunamaker (2002) 'A knowledge management framework for the support of decision making in humanitarian assistance/disaster relief'. Knowledge and Information Systems. 4(3). pp. 370-385. 